
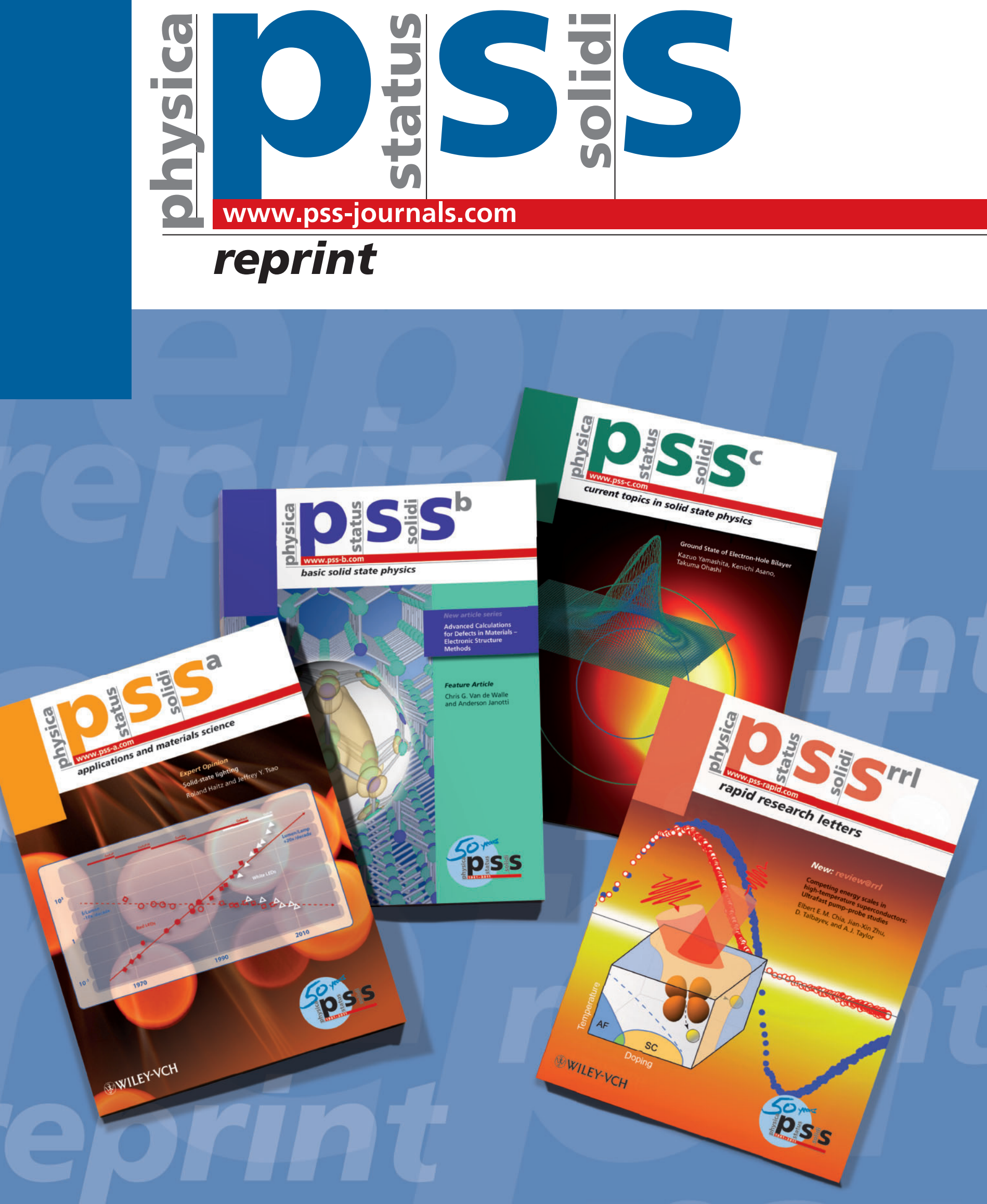


\title{
Structure and optical properties of silicon layers with GaSb nanocrystals created by ion-beam synthesis
}

\author{
F. Komarov ${ }^{*, 1}$, L. Vlasukova', O. Milchanin', A. Mudryi' ${ }^{2}$, B. Dunets' ${ }^{1}$, W. Wesch ${ }^{3}$, and E. Wendler ${ }^{3}$ \\ ${ }^{1}$ Belarusian State University, Nezavisimosti Ave. 4, 220030 Minsk, Belarus \\ ${ }^{2}$ Scientific and Practical Materials Research Centre, National Academy of Sciences of Belarus, P. Brovki Str. 17, \\ 220072 Minsk, Belarus \\ ${ }^{3}$ Institut für Festkörperphysik, Friedrich-Schiller-Universität Jena, Max-Wien-Platz 1, 07743 Jena, Germany
}

Received 8 February 2011, revised 9 June 2011, accepted 21 September 2011

Published online 17 October 2011

Keywords crystalline silicon, GaSb nanocrystals, high-fluence implantation, thermal treatment

*Corresponding author: e-mail komarovf@bsu.by, Phone: +375(172)12 48 33, Fax: +375(172)78 0417

We have studied the ion-beam synthesis of GaSb nanocrystals in Si by high-fluence implantation of $\mathrm{Sb}$ and $\mathrm{Ga}$ ions followed by thermal annealing. RBS, TEM/TED, RS, and photoluminescence (PL) were employed to characterize the implanted layers. It was found that the nanocrystals size increases from 5 to $60 \mathrm{~nm}$ in the samples annealed at $900{ }^{\circ} \mathrm{C}$ up to $20-90 \mathrm{~nm}$ in the samples annealed at $1100^{\circ} \mathrm{C}$. An existence of significant mechanical stresses within implanted layers has been detected. The stress values have been calculated from the shift of the Si first order Raman band. For the samples annealed at $900{ }^{\circ} \mathrm{C}$ a broad band in the spectral region of about $0.75-1.05 \mathrm{eV}$ is detected in the PL spectra. The nature of this PL band is discussed.
1 Introduction GaSb is a direct band-gap $\mathrm{A}^{3} \mathrm{~B}^{5}$ semiconductor with a narrow band-gap of about $0.75 \mathrm{eV}$. The synthesis of $\mathrm{GaSb}$ quantum dots inside the crystalline $\mathrm{Si}$ is of interest for applications in light emitting diodes and photodetectors operating in the IR range. InAs clusters have been formed on $\mathrm{Si}$ (001) by MBE-technique [1]. Such clusters covered with a $\mathrm{Si}$ cap layer show intense luminescence at $1.3 \mu \mathrm{m}$ at $7 \mathrm{~K}$. Light emitting diodes containing GaSb-quantum dots embedded in Si and operating at room temperature have been reported also [2]. Samples with GaSb-quantum dots were grown by MBE-technique on p-type Si (001). Post-growth annealing of these structures resulted in an appearance of a sharp line of luminescence localized at $900-\mathrm{meV}$ [2]. The other technique for fabricating III-V quantum dots is ion-beam synthesis of nanocrystals by means of ion implantation followed by thermal treatment. In this technique, high-fluence ion implantation produces a supersaturation of one or more implanted species in the nearsurface of crystalline or amorphous matrix. The embedded impurities then form precipitates within the host during thermal processing at elevated temperatures. InAs nanoclusters have been formed using this method in $\mathrm{SiO}_{2}$ and $\mathrm{Si}$ [3-5]. Unfortunately, thermal processing of implanted crystals results not only in precipitation and radiation damage recovery. Negative consequences of thermal processing exist such as a broadening of depth concentration profiles of embedded impurity and a net loss of implanted atoms because of diffusion that is favored at elevated temperature. Radiation defects are also taking part in the diffusion redistribution of embedded foreign atoms. Thus, on the one hand complex defect structures are formed during implantation and annealing at elevated temperatures, which significantly influence the formation, the size, and the depth distribution of the precipitates. On the other hand, the existence of the precipitates has also a strong effect on the quality of the surrounding crystalline host after the postimplantation annealing.

The purpose of this paper is to investigate the effect of post-implantation thermal processing on the diffusion redistribution of embedded foreign atoms and on the structural and optical properties of Si implanted with high fluence of both $\mathrm{Sb}$ and $\mathrm{Ga}$ ions.

2 Experimental The samples with the size of about $1 \times 1 \mathrm{~cm}^{2}$ were cut out of $\mathrm{n}-\mathrm{Si}(001)$ wafer and subsequently implanted with $\mathrm{Sb}\left(250 \mathrm{keV}, 5 \times 10^{16} \mathrm{~cm}^{-2}\right)$ and Ga ions 
$\left(350 \mathrm{keV}, 5 \times 10^{16} \mathrm{~cm}^{-2}\right)$ at $500{ }^{\circ} \mathrm{C}$. The samples were implanted under an angle of $7^{\circ}$ with respect to the surface normal without rotation. Afterwards, the samples were annealed using conventional furnace annealing and rapid thermal annealing (RTA) in inert ambient.

In order to analyze a depth distribution of the implanted atoms as well as to evaluate the damage of the implanted material, we applied Rutherford backscattering spectrometry in the combination with the channeling technique (RBS/C). RBS measurements were performed with $1.3 \mathrm{MeV}$ $\mathrm{He}^{+}$. The calculation of $\mathrm{Sb}$ and $\mathrm{Ga}$ concentrations in $\mathrm{Si}$ by RBS spectra is complicated by the overlapping of $\mathrm{Ga}$ and $\mathrm{Sb}$ peaks. To solve this problem, we measured RBS spectra at two angles of the incidence of $\mathrm{He}^{+}$ions into the samples: 0 and $50^{\circ}$ (in Kernel geometry).

The depth profiles of the implanted ions were obtained by simulation of spectra until they coincided completely with the experimental spectra recorded at two angles $\left(0\right.$ and $\left.50^{\circ}\right)$.

Structural modifications after implantation and annealing were studied by means of transmission electron microscopy (TEM) and diffraction (TED). The TEM investigations in plan view (PV) geometry were performed using a $200 \mathrm{keV}$-Hitachi $\mathrm{H}-800$. In order to obtain information from different depths the PV-TEM sample preparation was combined with a precise etching technique which allows stepwise clearing away defined thin layers.

The optical properties of samples were investigated by Raman spectroscopy (RS) and photoluminescence (PL).

Micro-Raman scattering experiments were carried out using a RAMANOR U-1000 dispersive spectrometer. The samples were excited with a laser beam $(\lambda=532 \mathrm{~nm})$ and the scattered light was detected in backscattering geometry. Raman spectra were recorded within the wave number range from 90 to $600 \mathrm{~cm}^{-1}$ at room temperature. PL spectra were recorded in the spectral region of $0.7-2 \mathrm{eV}$ using a $0.6 \mathrm{~m}$ grating monochromator and a cooled InGaAs detector. During the measurements the samples were mounted in a liquid He immersion cryostat, the $514.5 \mathrm{~nm}$ line of an argon ion laser was used to excite PL.

3 Results and discussion Figure 1 shows the depth profiles of $\mathrm{Ga}$ and $\mathrm{Sb}$ atoms in as-implanted and annealed samples, which were calculated from the RBS spectra. For comparison Fig. 1a depicts the ion distributions calculated with the computer code SRIM'2003. From Fig. 1b one can see that implantation at $500{ }^{\circ} \mathrm{C}$ already leads to strong broadening and significant reduction of the impurity concentration as compared to the SRIM calculation. This effect is weaker for $\mathrm{Ga}$ than for $\mathrm{Sb}$. The $\mathrm{Sb}$ depth profile shows an asymmetric broadening toward the surface of the sample.

The melting temperature of $\mathrm{GaSb}$ is $712^{\circ} \mathrm{C}$. In order to achieve a recovery of $\mathrm{Si}$ structure as complete as possible without $\mathrm{GaSb}$ melting, a first set of samples was annealed at $700{ }^{\circ} \mathrm{C}$ for $45 \mathrm{~min}$. PL spectra of the implanted samples are presented in Fig. 2. One can see that a broad asymmetric band with a maximum at $0.91 \mathrm{eV}$ dominates in the PL spectrum of
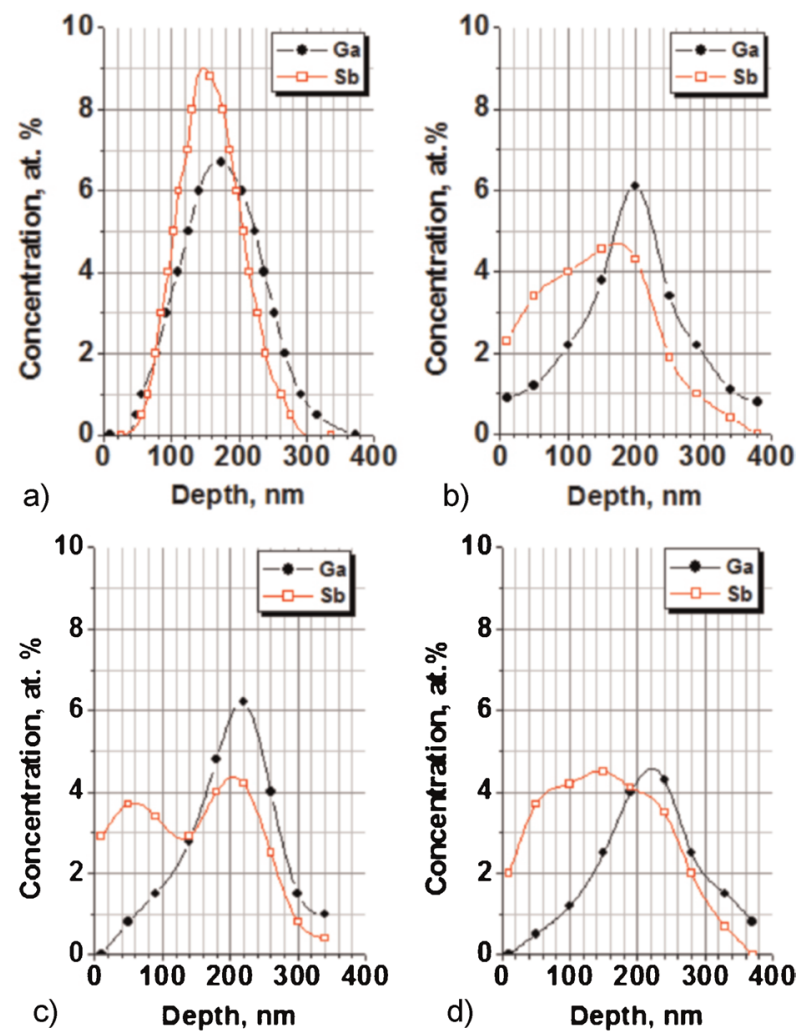

Figure 1 (online color at: www.pss-a.com) Distribution of impurities along the sample depth of $\mathrm{Si}$ implanted with $\mathrm{Sb}$ $\left(350 \mathrm{keV}, 5 \times 10^{16} \mathrm{~cm}^{-2}\right)$ and $\mathrm{Ga}$ ions $\left(250 \mathrm{keV}, 5 \times 10^{16} \mathrm{~cm}^{-2}\right)$ at $500{ }^{\circ} \mathrm{C}$ : (a) calculated with SRIM 2003 , (b-d) calculated from the RBS spectra depth profiles with (b) giving the result for as-implanted sample, (c) after furnace annealing $\left(900^{\circ} \mathrm{C}, 45 \mathrm{~min}\right)$, and (d) giving the result for the sample after RTA $\left(900^{\circ} \mathrm{C}, 30 \mathrm{~s}\right)$.

the as-implanted sample (Fig. 2a). Annealing at $700{ }^{\circ} \mathrm{C}$ leads to the disappearance of this band and to the appearance of an intensive band of exciton emission in $\mathrm{Si}$ peaked at $1.09 \mathrm{eV}$ and less intensive bands at 1.03 and $1.14 \mathrm{eV}$. We did not succeed to get channeled RBS spectra from the samples annealed at $700{ }^{\circ} \mathrm{C}$, what indicates an insufficient structural recovery of the implanted layers. Therefore, the implanted crystals were annealed at a temperature of $900{ }^{\circ} \mathrm{C}$ which exceeds the melting point of GaSb. The resulting depth profiles of the implanted species are presented in Fig. 1c and d. One can see that RTA leads to a strong broadening of the $\mathrm{Sb}$ profile toward the surface in comparison to the asimplanted sample. An increase of the thermal processing duration to 45 min results in a bimodal distribution of $\mathrm{Sb}$ atoms with maxima at 50 and $200 \mathrm{~nm}$. A mechanism of such $\mathrm{Sb}$ redistribution after an annealing is not clear. We suppose that an evolution of defect structure during an annealing causes such abnormal $\mathrm{Sb}$ diffusion to the surface. A similar bimodal distribution of species in $\mathrm{Si}$ implanted at $550{ }^{\circ} \mathrm{C}$ with high fluence of $\mathrm{Zn}^{+}$or $\mathrm{Ag}^{+}$ions and annealed at $700^{\circ} \mathrm{C}$ for $20 \mathrm{~h}$ was earlier reported by Meldrum et al. [6]. Authors of Ref. [6] extracted depth concentration profiles of 

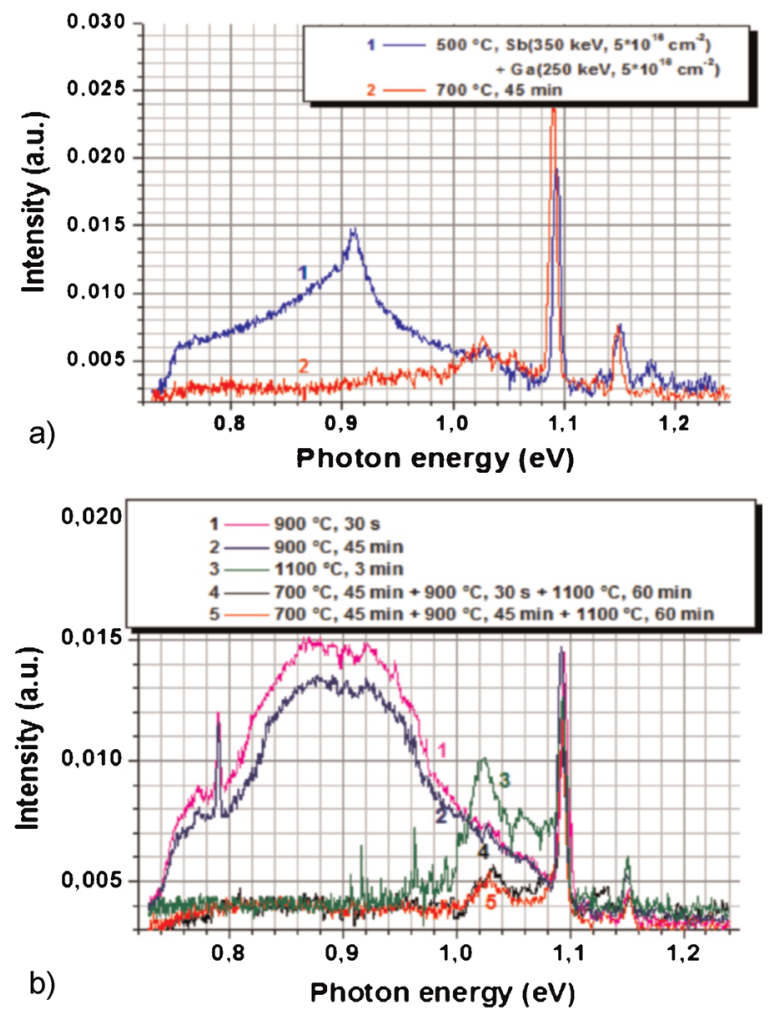

Figure 2 (online color at: www.pss-a.com) PL spectra of Si samples implanted with $\mathrm{Sb}$ and $\mathrm{Ga}$ and annealed in different regimes.

impurities from RBS spectra, too, and attributed such "twopeak" structure of these distributions to diffusion of impurity away from the peak of the implant concentration and toward the peak damage region at a shallower depth.

Figures 3 and 4 shows TEM-images and precipitate size distributions of $\mathrm{Si}$ implanted with $\mathrm{Sb}$ and $\mathrm{Ga}$ and annealed in different modes. We have not observed an amorphization of subsurface Si layer after "hot" implantation of $\mathrm{Sb}$ and $\mathrm{Ga}$ ions. Though, an implanted layer is characterized by essential damage. The annealing leads to substantial structure recovery. The surface region of the samples annealed at $900{ }^{\circ} \mathrm{C}$ for $45 \mathrm{~min}$ is a damaged layer containing microtwins and precipitates (Fig. 3a and c). The existence of a great number of microtwins may be caused by subsurface $\mathrm{Sb}$ atoms accumulation that is registered by RBS (Fig. 1b). It should be noted a bimodal size distribution of precipitates (a diffraction contrast from that ones did not disappear during sample tilting - Fig. 3a and b) for the sample annealed at $900{ }^{\circ} \mathrm{C}$ for $45 \mathrm{~min}$. The most of precipitates have a size between 10 and $50 \mathrm{~nm}$. Though, a part of ones has a size from 70 to $100 \mathrm{~nm}$. One can see small extra reflexes beside basic Si matrix reflexes at electron diffraction pattern (inset in Fig. 3a). These extra reflexes location is similar to the location of twin Si reflexes. Figure 3c shows a dark-field image taken in $\langle 220\rangle$-reflex of $\mathrm{Si}$ along with such extrareflex. One can see an interesting effect - "lighting" of nanocluster/Si interfaces (marked by arrows in Fig. 3c).

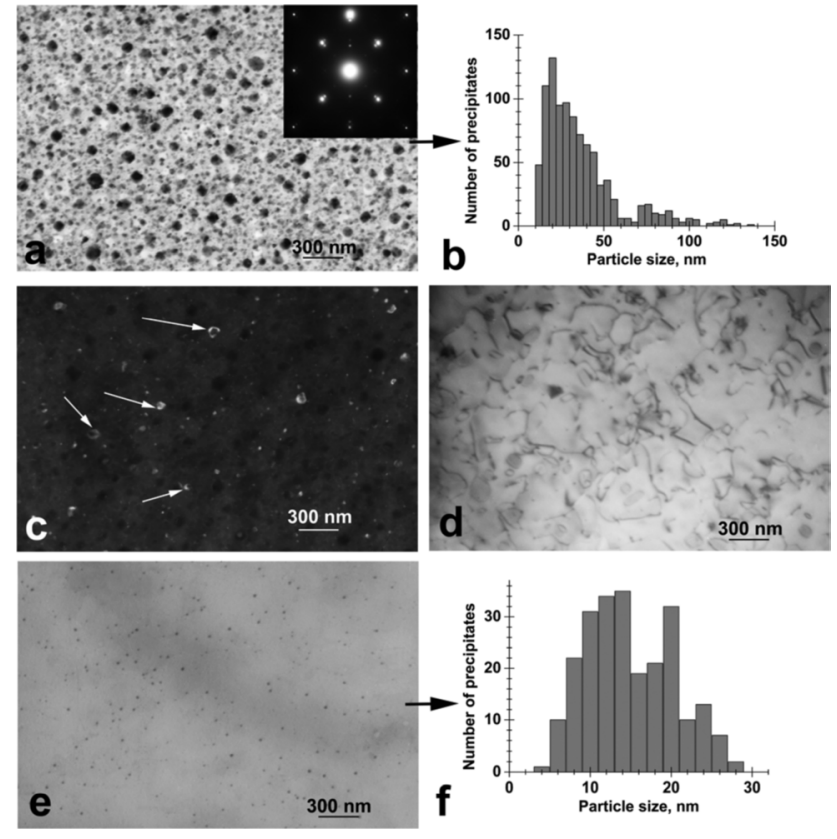

Figure 3 Bright-field (a, d, and e) and dark-field (c) TEM-images from $\mathrm{Si}$ after "hot" implantation of $\mathrm{Sb}\left(350 \mathrm{keV}, 5 \times 10^{16} \mathrm{~cm}^{-2}\right)$ and $\mathrm{Ga}\left(250 \mathrm{keV}, 5 \times 10^{16} \mathrm{~cm}^{-2}\right)$ and heat treatment $\left(900{ }^{\circ} \mathrm{C}\right.$, $45 \mathrm{~min}$ ) and precipitate size distributions (b and $\mathrm{f}$ ). The sample after the removal of surface layer of $190 \mathrm{~nm}$ thickness (d-f).
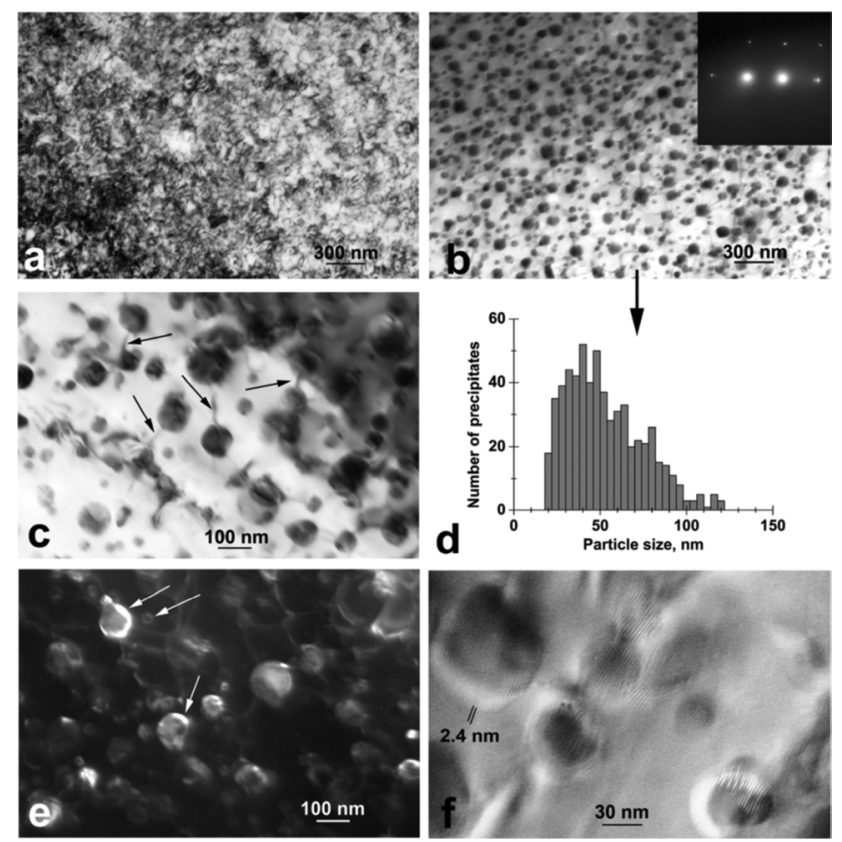

Figure 4 Bright-field (a-c and f) and dark-field (e) TEM-images from Si after "hot" implantation of $\mathrm{Sb}\left(350 \mathrm{keV}, 5 \times 10^{16} \mathrm{~cm}^{-2}\right)$ and $\mathrm{Ga}\left(250 \mathrm{keV}, 5 \times 10^{16} \mathrm{~cm}^{-2}\right)$ and heat treatment at $900{ }^{\circ} \mathrm{C}, 30 \mathrm{~s}$ (a) and $1100{ }^{\circ} \mathrm{C}, 60 \mathrm{~min}$ (b, c, e, and $\mathrm{f}$ ), and precipitate size distribution (d). The sample after the removal of $190 \mathrm{~nm}$ layer (a) and the sample without the removal of surface layer (b-f). 
According to the RBS data a maximum of embedded atoms is located at the depth of about $200 \mathrm{~nm}$. In order to investigate the structure of the implanted layer at this depth in detail, we have removed nearly $190 \mathrm{~nm}$ from the surface of selected samples by chemical etching. In the sample which was annealed at $900{ }^{\circ} \mathrm{C}$ for $45 \mathrm{~min}$, small precipitates and dislocation-like defects (dislocations and dislocation loops) can be distinguished after the $190 \mathrm{~nm}$-layer removing (Fig. 3d). In order to investigate precipitates in detail we have varied a samples tilt and got images without a diffraction contrast from dislocations. Figure $3 e$ shows TEM-image of thinned sample taken at such conditions. In accordance with the size distribution (Fig. 3f), the range of precipitates sizes are remarkably reduced in deeper regions of the sample, with the size being equal to $5-30 \mathrm{~nm}$.

Figure 4a depicts TEM-image of the sample annealed at $900{ }^{\circ} \mathrm{C}$ for $30 \mathrm{~s}$ applying RTA after the $190 \mathrm{~nm}$ layer removing. One can see that it is very difficult to distinguish precipitates and microtwins in this case. Hence, the total damage level in the sample after RTA is substantially higher in comparison with the sample subjected to the longer furnace annealing at the same temperature $\left(900^{\circ} \mathrm{C}\right)$. Though, PL spectra of the both samples are the same and characterized with a narrow band of exciton emission in $\mathrm{Si}$ at $1.09 \mathrm{eV}$ and a broad band at $0.75-1.05 \mathrm{eV}$ (Fig. 2b). A similar band was observed earlier in the PL spectra of InAs nanocrysals grown on Si wafers by MBE [1] or synthesized by high-fluence ion implantation of In and As into Si $[4,5]$. That band was ascribed to InAs nanocrystals. In the experiments under consideration here, the similar band is registered in PL spectra of Si implanted with Sb and Ga ions. Thus, the question about the nature of that band arises. Let us assume that a basic contribution to the luminescence in this energy region arises from charge carrier recombination in $\mathrm{GaSb}$ nanocrystals. Then, the luminescence intensity should be higher in the sample with the more perfect crystalline structure which is the one being annealed to the longer time. However, this is obviously not the case. Therefore it is more probable to assume that the discussed band is related to radiative recombination at the nanocrystal/Si interfaces. In such interpretation it may be expected that the frequency of the nanocrystal-related band in the PL spectrum is practically independent of the composition of the nanocrystals and of the method of synthesis (MBE or implantation) and is defined by the nanocrystal/Si interface properties, and quantum confinement in PL is a secondary effect only. It should be noted that in some papers [7-9], the surface states at the nanocrystal $\mathrm{Si} / \mathrm{SiO}_{2}$ interface region were considered to have a great influence on the PL properties and the shift of the PL peak was associated with the change of the interface region. A phononless line of $0.79 \mathrm{eV}$ is observed in both spectra. In our opinion, it is related to the recombination of bound excitons on ion-induced defects [interstitial carbon interstitial oxygen $\left(\mathrm{C}_{\mathrm{i}}-\mathrm{O}_{\mathrm{i}}\right.$ pairs $)$ [10]].

A part of samples was additionally annealed $\left(1100^{\circ} \mathrm{C}\right.$, $1 \mathrm{~h})$ to achieve a better recovery of structure. Figure $4 \mathrm{~b}-\mathrm{f}$ depicts TEM-images of these samples. In this case the crystal precipitates are also observed. It is proved by the presence of Moiré contrast (Fig. 4f). The size of the most of precipitates is in the range of $20-90 \mathrm{~nm}$. Though, there are precipitates with the size up to $120 \mathrm{~nm}$ (Fig. 4d). One can see dislocation lines connecting the largest precipitates (marked by arrows at Fig. 4c and e). It should be noted "lighting" of nanocrystal/Si interfaces at dark-field image (Fig. 4e). The same effect was observed for the samples annealed at $900{ }^{\circ} \mathrm{C}$ for $45 \mathrm{~min}$ (Fig. 3c). A clearance of observed effect's nature is a subject of further investigations. After the annealing at $1100{ }^{\circ} \mathrm{C}$ the band at $0.75-1.05 \mathrm{eV}$ disappears from the PL spectrum (Fig. 2b). As for the samples annealed at $700{ }^{\circ} \mathrm{C}$, the intensive band of exciton emission in $\mathrm{Si}$ at $1.09 \mathrm{eV}$ and less intensive bands at 1.03 and $1.14 \mathrm{eV}$ are registered in a PL spectrum of the samples processed at $1100^{\circ} \mathrm{C}$.

In order to identify nanocrystals RS was used. Figure 5 depicts RS spectra of as-implanted and annealed samples.

The Raman spectrum of an as-implanted sample (curve 1) reveals a narrow peak at $512 \mathrm{~cm}^{-1}$ corresponding to zone-center phonons scattering of crystalline silicon. The presence of this peak confirms the crystalline state of the silicon matrix after the high-fluence implantation of heavy $\mathrm{Sb}$ and $\mathrm{Ga}$ ions at elevated temperature. It should be noted that a significant shift toward low frequencies occurs in comparison with the peak's position at $521 \mathrm{~cm}^{-1}$ for undamaged Si [11]. We suggest that this shift indicates an existence of significant mechanical strains within the implanted layer. Perhaps, that stress is caused by the accumulation of impurity atoms (for the most part, $\mathrm{Sb}$ ) in the sub-surface layer. Annealing leads to a shift to high frequencies (up to $518 \mathrm{~cm}^{-1}$ after processing at $1100^{\circ} \mathrm{C}$ ) and to an increase of the intensity of the discussed peak. Though, the annealing regimes used in our experiment do not completely eliminate the stress in the implanted layer. We have detected the RS spectrum of the sample annealed at $900{ }^{\circ} \mathrm{C}$ for $45 \mathrm{~min}$ after the etching of a $190 \mathrm{~nm}$-layer from its

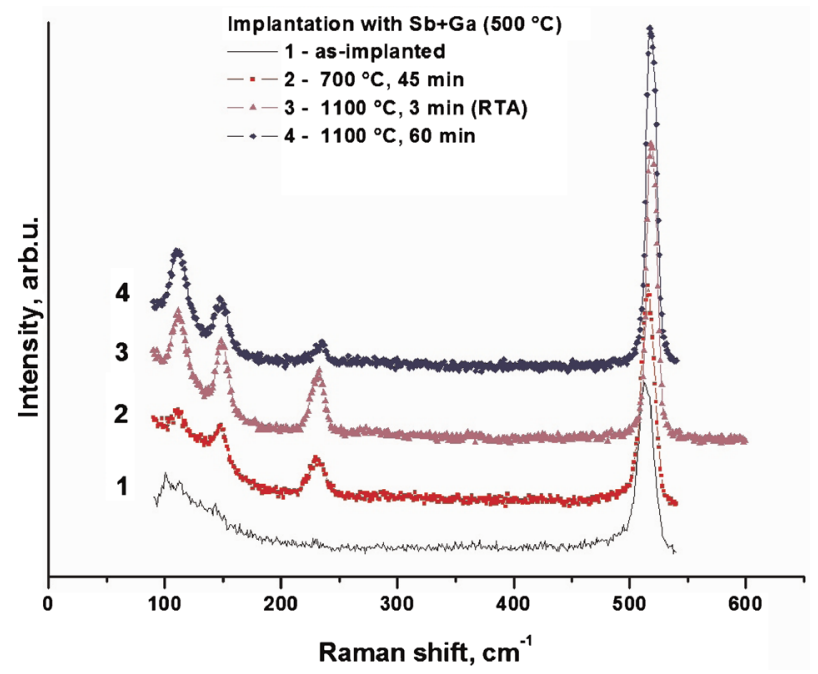

Figure 5 (online color at: www.pss-a.com) RS spectra of $\mathrm{Si}$ samples implanted with $\mathrm{Sb}$ and $\mathrm{Ga}$ and annealed in different modes. 
surface and registered the position of discussed peak at $521 \mathrm{~cm}^{-1}$ as for un-damaged $\mathrm{Si}$ (not shown). Hence, the thickness of the stressed layer is lower than $190 \mathrm{~nm}$.

This stress can be taken into account by assuming a model in which the residual stress is uniformly distributed in the scattering volume [12-14]. In such a case, the stress does not affect the shape of the Raman spectra [15], and the only effect of stress is a shift of the spectra. According to this treatment, the wave number of the first order Raman band in the stressed layer, $w_{\mathrm{p}}$ is shifted in relation to the wave number of the first order Raman band in the absence of stress effects, $w_{0}$. This latter parameter corresponds to the position of the Raman line from stress free crystalline silicon $\left(521 \mathrm{~cm}^{-1}\right)$. Then the stress induced shift is given by [12]:

$$
\Delta w_{\mathrm{s}}=w_{0}-w_{\mathrm{p}}
$$

On the basis of an in-plane stress model, we can estimate the magnitude of such stress, $\sigma$ to be proportional to the stress induced wave number shift $\Delta w_{\mathrm{s}}[15,16]$ :

$$
\sigma(\mathrm{MPa})=250 \Delta w_{\mathrm{s}}\left(\mathrm{cm}^{-1}\right)
$$

According to this formula, the tensile stress amounts to $2.25 \mathrm{GPa}$ for as-implanted samples and to $750 \mathrm{MPa}$ for samples annealed at $1100{ }^{\circ} \mathrm{C}$. A compressive stress should induce a shift to high frequency.

The annealing results in the appearance of additional bands in the frequency region of $110-235 \mathrm{~cm}^{-1}$ in RS spectra. The peak at $233 \mathrm{~cm}^{-1}$ is attributed to LO-phonon scattering of crystalline GaSb [11]. Its intensity changes with annealing temperature and duration and its largest value occurs for the sample processed at $1100{ }^{\circ} \mathrm{C}$ for $3 \mathrm{~min}$. Additional peaks at 112 and $149 \mathrm{~cm}^{-1}$ are registered in RS spectra of annealed samples which are the characteristic lines for $\mathrm{Sb}$. We attribute them to LO- and TO-phonon scattering of crystalline $\mathrm{Sb}$. For bulk $\mathrm{Sb}$ the frequencies of LO- and TOphonons are 113 and $152 \mathrm{~cm}^{-1}$ [17], respectively. Probably, the thermal processing of the samples with high Sb and Ga concentrations leads to the formation of both $\mathrm{GaSb}$ and $\mathrm{Sb}$ precipitates within the Si matrix. A similar situation was reported by other authors for $\mathrm{Si}$ implanted at $500{ }^{\circ} \mathrm{C}$ with high fluence of As and In ions [4]. After annealing both InAs and crystalline In precipitates were detected by X-ray diffraction.

4 Conclusions We have demonstrated a possibility to produce $\mathrm{GaSb}$ nanocrystals in Si by means of high-fluence implantation of $\mathrm{Sb}$ and $\mathrm{Ga}$ ions and thermal processing. Implantation at $500{ }^{\circ} \mathrm{C}$ with $\mathrm{Sb}\left(250 \mathrm{keV}, 5 \times 10^{16} \mathrm{~cm}^{-2}\right)$ and Ga ions $\left(350 \mathrm{keV}, 5 \times 10^{16} \mathrm{~cm}^{-2}\right)$ followed by annealing $\left(900{ }^{\circ} \mathrm{C}, 45 \mathrm{~min}\right)$ resulted in the formation of $\mathrm{GaSb}$-phase precipitates with sizes from 5 to $60 \mathrm{~nm}$. Thermal treatment at $1100^{\circ} \mathrm{C}$ leads to the growth of precipitate sizes to $20-90 \mathrm{~nm}$. The tensile stresses in implanted layers were calculated from $\mathrm{RS}$ data. These stresses are attributed to accumulation of $\mathrm{Sb}$ atoms in the sub-surface layer and amounts to $2.25 \mathrm{GPa}$ in as- implanted samples and to $750 \mathrm{MPa}$ for samples annealed at $1100{ }^{\circ} \mathrm{C}$. It was found that the low-temperature PL spectrum of $\mathrm{Si}$ with nanocrystals depends on thermal processing. For samples after annealing at $900{ }^{\circ} \mathrm{C}$ a broad band in the region of $0.75-1.05 \mathrm{eV}$ is registered. For samples processed at 700 or $1100{ }^{\circ} \mathrm{C}$ the narrow band of exciton emission in $\mathrm{Si}$ at $1.09 \mathrm{eV}$ and bands at 1.03 and $1.14 \mathrm{eV}$ are observed.

Acknowledgements This work was partly supported by the Belarusian Republican Foundation for Fundamental Research (grants F10R-143 and T10R-142).

\section{References}

[1] R. Heitz, N. N. Ledentsov, D. Bimberg, A. Yu. Egorov, M. V. Maximov, V. M. Ustinov, A. E. Zhukov, Zh. I. Alferov, G. E. Cirlin, I. P. Soshnikov, N. D. Zakharov, P. Werner, and U. Gösele, Physica E 7, 317 (2000).

[2] M. Jo, N. Yasuhara, Y. Sugawara, K. Kawamoto, and S. Fukatsu, Abstracts of European Mater. Res. Soc. Spring Meeting: Materials Science and Device Issues for Future Sibased technologies, Strasbourg (France), May 31-June 3, 2005 D/PI. 37.

[3] F. F. Komarov, L. A. Vlasukova, O. V. Milchanin, P. I. Gaiduk, V. N. Yuvchenko, and S. S. Grechnyi, Vacuum 78, 361 (2005).

[4] A. L. Tchebotareva, J. L. Brebner, S. Roorda, and C. W. White, Nucl. Instrum. Methods Phys. Res. B 175-177, 187 (2001).

[5] F. Komarov, L. Vlasukova, W. Wesch, A. Kamarou, O. Milchanin, S. Grechnyi, A. Mudryi, and A. Ivaniukovich, Nucl. Instrum. Methods Phys. Res. B 266, 3557 (2008).

[6] A. Meldrum, S. Honda, C. W. White, R. A. Zuhr, and L. A. Boatner, J. Mater. Res. 16, 2670 (2001).

[7] Y. Kanemitsu and S. O. Kamoto, Phys. Rev. B 56, R1696 (1997).

[8] Y. N. Dinh, Y. Y. Chase, M. Balooch, W. J. Siekhaus, and F. Wooden, Phys. Rev. B 54, 5029 (1996).

[9] X. D. Zhou, F. Ren, X. H. Xiao, G. X. Cai, and C. Z. Jiang, Nucl. Instrum. Methods Phys. Res. B 267, 3437 (2009).

[10] R. Souer, J. Weber, J. Sholz, E. K. Weber, K. H. Kusters, and H. Alexander, Appl. Phys. A 36, 1 (1985).

[11] M. Landölt and J. Börnstein, Numerical Data and Functional Relationships in Science and Technology, New Series (Springer-Verlag, Berlin-Heidelberg, 1982).

[12] H. Xia, Y. Z. He, Z. C. Wang, W. Zhang, X. N. Ziu, X. K. Zhang, and D. Feng, Appl. Phys. 78, 6705 (1995).

[13] M. Yang, D. Huang, P. Hao, F. Zhang, X. Hou, and X. Wang, Appl. Phys. 75, 651 (1994).

[14] J. Macia, E. Martin, A. Perez-Rodrigues, J. Jimenez, J. R. Morante, B. Aspar, and J. Margail, Appl. Phys. 82, 3730 (1997).

[15] E. Anastassakis and E. Yiarokapis, Appl. Phys. 62, 3346 (1987).

[16] E. Anastassakis, in: Physical Problems in Microelectronics, Proceedings of the 4th International School ISPPM, edited by J. Kassavod (Varna, Bulgaria, 1985), p. 128.

[17] Analytical Applications of Raman Spectroscopy, edited by M. J. Pelletier (Blackwell Science, Cambridge, MA, 1999), p. 478. 